\title{
Doe wel en zie wél om: de terugkijkfunctie
}

\author{
Anja M. Kremer, Wout E.L. de Boer, Jan J.M. Besseling, J.B. Titus Schaafsma
}

Het verzuimpercentage in Nederland ligt de afgelopen jaren iets boven de $4 \%$. $^{\mathrm{I}, 2}$ Een aanzienlijk deel van het totale verzuim komt voor rekening van een relatief kleine groep werknemers die langdurig verzuimt. Langdurig verzuim is een direct probleem voor de werknemer én een risico op definitieve uitval uit arbeid. ${ }^{3}$ Verzuim brengt voor de werkgever organisatieproblemen en hoge kosten mee. Een goede verzuimbegeleiding is daarom van groot belang. De verzuimbegeleiding wordt meestal gedaan door de bedrijfsarts. Verwacht wordt dat de bedrijfsarts bij langdurige gevallen (ongeveer een jaar) afstand neemt en goed in ogenschouw neemt of het juiste spoor wordt gevolgd. Dat is het zogeheten opschudmoment. Bij zeer langdurige gevallen doet de verzekeringsarts dat in de zogeheten terugkijkfunctie bij de aanvraag in het kader van de WIA. ${ }^{4}$ Ook kan de verzekeringsarts meekijken in het kader van een deskundigenoordeel.

Van langdurige ziektegevallen is niet altijd duidelijk waarom het verzuim zo lang heeft geduurd. Zicht daarop ontbreekt tot nu toe. Het is goed mogelijk dat er kansen zijn blijven liggen in de behandeling, de begeleiding of het aanpassen van werk. Een kwalitatieve casestudie uit 2004 onder langdurig verzuimende werknemers, hun werkgevers, hun bedrijfsarts, hun huisarts en verzekeringsarts (waar dat van toepassing was) geeft aan dat er kansen blijven liggen. In die studie was drie kwart van de langdurig verzuimenden geen

Dr. A.M. Kremer werkte als arts-onderzoeker bij TNO, thans 'in-between jobs'.

Dr. W.E.L. de Boer werkte als senior arts-onderzoeker bij TNO, thans bij ASIM, Universitätsspital Basel, Zwitserland.

Drs. J.J.M. Besseling werkt als senior onderzoeker bij TNO Work and Employment. Drs. J.B.T. Schaafsma is bedrijfsarts bij Achmea Vitale.

\section{CORRESPONDENTIEADRES}

E-mail: jan.besseling@tno.nl.

\section{SAMENVATTING}

In een pilotonderzoek is onderzocht of vermijdbaar verzuim achteraf is te signaleren bij werknemers die een jaar verzuimen. Hiertoe hebben I3 bedrijfsartsen over 72 werknemers met één jaar verzuim een vragenlijst ingevuld. Ook 65 werknemers deden dat en van 55 casus was er zowel informatie van de bedrijfsarts als van de werknemer. Werknemers en bedrijfsartsen signaleren in respectievelijk $42 \%$ en 5 I \% van de gevallen gemiste kansen in het verzuimtraject bij één of meer van de domeinen: de curatieve zorg, de arbozorg, de werkgever en/of de werknemer.

De bedrijfsartsen signaleren bij $8 \%$ van de casus evident gemiste kansen en bij 43\% mogelijk gemiste kansen. Van de werknemers is 3I\% van mening dat hun verzuim korter had kunnen duren en I I \% dat het voorkomen had kunnen worden. Op casusniveau waren werknemer en bedrijfsarts het in 35\% van de gevallen eens dat er geen gemiste kansen waren. In $7 \%$ van de gevallen waren ze het volledig eens over de aard van de gemiste kansen, in $9 \%$ waren ze het gedeeltelijk eens, en in $49 \%$ van de gevallen waren ze het niet eens over de aard van de gemiste kansen. De bedrijfsartsen signaleerden bij werknemers die toegang hadden tot een provider of een re-integratiebedrijf, significant minder vaak gemiste kansen. Werknemers die toegang hadden tot een provider, zagen echter even vaak gemiste kansen als de werknemers die geen toegang hadden. Als de kansen niet gemist zouden zijn, zou volgens de bedrijfsarts dit bij de meerderheid hebben geleid tot sneller herstel, korter verzuim en minder arbeidsongeschiktheid. Terugkijken op het opschudmoment lijkt een waardevol instrument te zijn voor de bedrijfsarts in de verzuimbegeleiding. Aandacht voor de validiteit van de terugkijkfunctie lijkt gezien de grote verschillen in bevindingen tussen werknemers en bedrijfsartsen wenselijk. Een groter en representatief onderzoek is nodig om deze bevindingen te toetsen en te kwantificeren.

'glad' geval waar evident afgekoerst werd op het optimaal haalbare resultaat. 'In enkele gevallen is sprake van volkomen miscommunicatie tussen verschillende actoren, die elkaar uiteenlopende motieven en plannen toedichten. Dit zijn de gevallen die passen in Donners beeldspraak van het WAO-proces als een Griekse tragedie: ieder speelt keurig zijn eigen rol, maar het samenstel van de rollen leidt onafwendbaar tot noodlot.'5 In een Nederlands onderzoek onder 2.954 werkenden gaf I $5 \%$ van de werknemers met verzuim aan dat het verzuim korter had gekund of voorkomen had kunnen worden. ${ }^{6}$ Vermijdbaar verzuim lag op vier domeinen: de werknemer zelf, de werkgever en/of werk(omstandigheden), de professionals uit de arbozorg en de curatieve behandeling. In werktijd uitgedrukt
TERUGKIJKFUNCTIE, GEMISTE KANSEN BIJ LANGDURIC VERZUIM, VISIE WERKNEMER, VISIE BEDRIJFSARTS 
was 2 I, $5 \%$ van het ziekteverzuim mogelijk vermijdbaar: de vermijdbare verzuimfractie was I $2,9 \%$ voor privéfactoren, I $3,6 \%$ voor werkgerelateerde factoren en I0,I\% voor factoren in de (bedrijfs)gezondheidszorg. Het is de vraag of anderen dan de werknemers dit ook zo zien. Een neutrale beoordeling daarvan zou kunnen komen van de verzekeringsarts als invulling van de terugkijkfunctie bij de WIA-aanvraag. Een onderzoek daarnaar is door ons voorgesteld, maar UWV weigerde haar medewerking zodat wij de vraag bij een arbodienst zijn gaan stellen. Wij onderzochten of er bij verzuimgevallen van één jaar kansen waren blijven liggen in de behandeling, de begeleiding of het aanpassen van werk, volgens zowel de bedrijfsarts als de werknemer zelf. Het moge duidelijk zijn dat ook anderen, zoals de werkgever en artsen uit de curatieve sector, een visie kunnen hebben op de vraag of het verzuim voorkomen had kunnen worden, dan wel korter had kunnen duren. Aangezien hun bijdrage (naar verwachting) facultatief zal zijn bij de invulling van de terugkijkfunctie door de verzekeringsarts bij de WIA-aanvraag, zijn zij in dit onderzoek buiten beschouwing gebleven.

Voor dit onderzoek hebben wij de volgende vragen geformuleerd:

1. Hoe vaak signaleren bedrijfsartsen en werknemers gemiste kansen in het verzuimtraject en aan welke domeinen worden de gemiste kansen toegeschreven?

2. Hoe vaak zijn de bedrijfsarts en werknemers het met elkaar (on)eens over waar de gemiste kansen liggen?

3. Worden bij werknemers die geen toegang hebben tot arbeidsgerelateerde zorg (rugschool, CGT e.d.) of een re-integratiebedrijf, vaker gemiste kansen gesignaleerd dan bij werknemers die er wel toegang tot hebben?

4. Hoe vaak leidt de signalering gemiste kans tot een daadwerkelijke actie van de bedrijfsarts?

I Tijdens het opschudmoment ziet de bedrijfsarts bij de helft (mogelijk) gemiste kansen.

I Van de langdurig verzuimende werknemers ziet $40 \%$ gemiste kansen.

I De overeenstemming tussen de visie van de werknemer en de bedrijfsarts is beperkt.
Een gemiste kans is in dit onderzoek geoperationaliseerd als het doen of juist nalaten van een activiteit of het optreden van een omstandigheid waardoor werkhervatting werd belemmerd of vertraagd. Gemiste kansen kunnen liggen in vier domeinen:

1. de curatieve zorg;

2. de arbozorg (bedrijfsarts, zorg vanuit zorgarrangementen en providers);

3. werk (inclusief werkgever);

4. werknemer (inclusief zijn/haar privéomgeving).

\section{METHODE}

We hebben gebruik gemaakt van de beoordelingen van twintig bedrijfsartsen van een grote, landelijk werkende arbodienst. Het inclusiecriterium betrof de beoordelingen die de bedrijfsartsen uitvoerden tussen oktober 2009 en maart 2010 bij werknemers die I I tot I 3 maanden verzuimden. Met deze beoordeling wordt invulling gegeven aan het opschudmoment, de wettelijk verplichte eerste jaarsevaluatie. Na elke beoordeling vulden de bedrijfsartsen na het spreekuurcontact een onlinevragenlijst in over mogelijk gemiste kansen bij de betreffende werknemer. De bedrijfsartsen vroegen aan de betrokken werknemers of zij bereid waren mee te doen aan een onderzoek over 'Begeleiding en behandeling tijdens ziekteverzuim' en gaven hen een vragenlijst mee. De ingevulde vragenlijsten konden de werknemers naar TNO sturen.

\section{Vragenlijsten}

De bedrijfsartsen beantwoordden vragen over de werksituatie van de werknemer voorafgaande aan de ziekmelding (type werk, type dienstverband), reden ziekteverzuim (maximaal drie diagnoses), begeleidingstraject eerste verzuimjaar (begeleidingsafspraken werkgever/arbodienst/reintegratiebedrijf), verwijzingen naar providers of re-integratiebedrijven of andere dienstverleners en gemiste kansen (domein, acties, gevolgen). De vraag over gemiste kansen luidde: 'Wat is, op basis van de gegevens die u ter beschikking heeft, uw beoordeling van het beloop van het verzuim (denkend aan de gezondheid werknemer, duur verzuim), en mate van arbeidsongeschiktheid?' In de toelichting hebben we aangegeven dat gemiste kansen die inmiddels ongedaan gemaakt zijn, gerekend moeten worden tot gemiste kansen. De antwoordmogelijkheden waren:

I Er zijn evident gemiste kansen

I Er zijn mogelijk gemiste kansen

I Er zijn geen gemiste kansen

I Is niet te beoordelen. 
Ook werd gevraagd naar de gevolgen van een gemiste kans voor de (I) gezondheid van de werknemer, (2) de duur van het verzuim en (3) de mate van arbeidsongeschiktheid.

De werknemersvragenlijst bevatte vragen over type werk, huidige werksituatie, klachten bij ziekmelding, of ziekmelding het gevolg was van werk en/of privéomstandigheden, of naar hun inschatting het verzuim korter had gekund of voorkomen had kunnen worden en, zo ja, wat volgens hen dan anders of beter had gekund in het domein van de curatieve sector/eerste lijn, in de begeleiding door arbodienst of re-integratiebedrijf, de begeleiding door werkgever of leidinggevende en bij de werknemer zelf. Zowel de werknemers als de bedrijfsarts konden meerdere domeinen aangeven.

\section{RESULTATEN}

Van de 20 bedrijfsartsen hebben $\mathrm{I} 3$ een of meerdere vragenlijsten ingevuld (spreiding I-I6). In totaal hebben ze gegevens ingevuld over 72 werknemers, terwijl zij aan 82 werknemers een vragenlijst hebben afgegeven. Vijfenzestig werknemers hebben de vragenlijst ingevuld. Van 55 verzuimgevallen hebben we een respons van de werknemer én de betrokken bedrijfsarts.

\section{Vóórkomen van gemiste kansen}

De bedrijfsartsen waren van mening dat bij 37 van de 72 gevallen $(5 \mathrm{I} \%)$ sprake was van evident (6) of mogelijk gemiste kansen (3I). In één geval gaf de bedrijfsarts aan het niet te kunnen beoordelen. Van de 65 werknemers waren er 27 van mening (42\%) dat hun verzuim korter had gekund (20) of voorkomen had kunnen worden (7). Volgens de bedrijfsartsen waren er vooral verbetermogelijkheden in het domein curatieve zorg, volgens de werknemers in de curatieve zorg en bij de werk(gever) (tabel I).

\section{SUMMARY}

Do well but do look back: the review function

A pilot study investigated whether it is possible to identify in retrospect any avoidable sickness absence for employees after one year of sick leave. To this end $\mathrm{I} 3$ occupational physicians completed a questionnaire about 72 employees after one year of absence. This was also done by 65 employees. In 55 cases data was available from both occupational physician and employee. Employees and occupational physicians identified in respectively $42 \%$ and $51 \%$ of cases missed opportunities for favouring return to work during the course of sick leave in one or more of the following domains: curative care, occupational health and safety care, the employer and the employee.

The occupational physicians found in $8 \%$ of cases evidently missed opportunities and in $43 \%$ possibly missed opportunities. Of the employees $3 \mathrm{I} \%$ stated that the duration of their sick leave could have been shorter and II\% thought it could have been prevented altogether. At a case level, employees and occupational physicians agreed in $35 \%$ of cases that there had not been any missed opportunities. In $7 \%$ of cases they fully agreed on the nature of the missed opportunities, in $9 \%$ they partially agreed and in $49 \%$ they did not agree on the nature of the missed opportunities. The occupational physicians detected significantly fewer missed opportunities with employees that had access to a care provider or a reintegration service. Employees with access to a care provider however, perceived missed opportunities as often as employees without access. According to the occupational physicians it would have meant a faster recovery, shorter sick leave and less disability for the majority of cases if the opportunities had been taken advantage of. Reviewing the socio-medical history at the 'shake up moment', the obligatory evaluation after one year of sick leave, appears to be a valuable instrument in socio-medical counselling for the occupational physician. Considering the large differences in the findings of the employees and occupational physicians, attention for the validity of the review function is desirable. A larger and representative study is needed in order to test and quantify the findings.

In de verdere rapportage worden de beide antwoordcategorieën van de werknemer (verzuim had korter gekund en het had voorkomen kunnen worden) samengevoegd onder de noemer

\begin{tabular}{|c|c|c|c|c|}
\hline \multicolumn{5}{|c|}{\begin{tabular}{|l} 
Tabel 1 \\
Gemiste kansen (bedrijfsartsen) of verbeteringen (werknemer)
\end{tabular}} \\
\hline & \multicolumn{2}{|c|}{ Bedrijfsarts $(n=72)$} & \multicolumn{2}{|c|}{ Werknemer $(n=65)$} \\
\hline & aantal & $\%$ & aantal & $\%$ \\
\hline \multicolumn{5}{|c|}{ Evident gemiste kans, zv had voorkomen } \\
\hline kunnen worden & 6 & $8 \%$ & 7 & $11 \%$ \\
\hline \multicolumn{5}{|c|}{ Mogelijk gemiste kans, zv had korter } \\
\hline gekund & 31 & $43 \%$ & 20 & $31 \%$ \\
\hline Totaal & 37 & $51 \%$ & 27 & $42 \%$ \\
\hline \multicolumn{5}{|l|}{ Waarvan in domein } \\
\hline curatieve zorg & 23 & $62 \%$ & 17 & $63 \%$ \\
\hline arbozorg & 14 & $38 \%$ & 8 & $30 \%$ \\
\hline werk(gever) & 13 & $35 \%$ & 14 & $52 \%$ \\
\hline \multirow[t]{2}{*}{ werknemer } & 10 & $27 \%$ & 10 & $37 \%$ \\
\hline & & $(100 \%=37)$ & & $(100 \%=27)$ \\
\hline
\end{tabular}


'gemiste kansen' evenals de antwoorden evident en de mogelijk gemiste kansen volgens de bedrijfsarts.

De respondenten zagen ook gemiste kansen bij zichzelf: de bedrijfsarts I 3 keer (35\%) en de werknemer Io keer (37\%). De bedrijfsartsen die gemiste kansen zagen, zagen dat niet op één domein maar gemiddeld op I,6 en de werknemers gemiddeld op I,8 domein.

De bedrijfsarts gaf ook de diagnose van het verzuim. De meeste werknemers (40\%) hadden als eerste diagnose een ziekte van het bewegingsstelsel, gevolgd door de diagnose psychische stoornissen (28\%), overige aandoeningen (25\%) en ziekten van het hart- en vaatstelsel (7\%). Bij de eerste drie grotere groepen schommelde het percentage gemiste kansen rond het totaal gemiddelde van 5I\%, namelijk tussen 48 en 55\%.

Domein curatieve zorg (werknemer)

Als er sprake is van meerdere op elkaar ingrijpende klachten, kom je in een wondere wereld terecht. De neuroloog bemoeit zich met alleen het zenuwstelsel. De orthopeed alleen met het bottenstelsel. Van de pijnbehandelaar verwacht je een integrale aanpak, maar dat is een anesthesist en die stopt - of probeert te stoppen - de werking van de pijnprikkels. Op mijn oude klachten had ik na een jarenlange zoektocht via manuele therapie en yoga een prima manier van leven gevonden. Sinds er twee jaar geleden nieuwe klachten zijn bijgekomen, is de zoektocht opnieuw begonnen.

Domein arbozorg (werknemer)

Er zijn gesprekken geweest met de werkgever vanuit de bedrijfsarts. Adviezen zijn niet opgevolgd. Verder heeft de bedrijfsarts volgens mij de ernst van de ziekte/klachten onderschat. Probeerde vervolgens veel druk op mij te zetten, wat mij juist in het genezingsproces teruggeworpen heeft.
De 7 werknemers die van mening waren dat het verzuim voorkomen had kunnen worden, wezen daarbij vooral op de rol van de werkgever die knelpunten niet aanpakte, werkdruk liet oplopen, zich niet inspande om ander werk te vinden, of de basis voor een burn-out legde door de werknemer en een aantal collega's te proberen te ontslaan op een moment dat de gezondheid van betrokkene kwetsbaar was. Overigens gaven 5 werknemers aan dat ze ook zelf beter of eerder grenzen hadden moeten aangeven en/of duidelijker aan de bel hadden moeten trekken.

Overeenkomsten en verschillen

Van de 55 casus waarvan we van beiden informatie hebben, waren bij I I casus (20\%) arts en werknemer het erover eens dat er gemiste kansen waren. In 25 casus (45\%) was het alleen de werknemer (8) of de bedrijfsarts (I7) die verbetermogelijkheden zag. Dit betekent dat in I9 casus (35\%) er geen onvolkomenheden in de verzuimbegeleiding gesignaleerd werden door arts of werknemer. Op casusniveau zijn bedrijfsarts en werknemer het 4 keer volledig eens over de aard van het domein en 7 keer zijn ze het gedeeltelijk eens over het domein (blijkt niet uit tabel).

Bij de II casus waar de bedrijfsartsen en de betrokken werknemers beiden gemiste kansen/ verbeterpunten zien (tabel 2), is er overeenstemming dat er (relatief veel) gemiste kansen zijn door de curatieve sector. De arbozorg zorgt in 7 van de II casus voor gemiste kansen, maar slechts in 2 gevallen is er overeenstemming tussen de visie van de werknemer en die van de bedrijfsarts. In 2 van de 3 casus dat de werkgever een rol gespeeld heeft, zijn werknemer en bedrijfsarts het eens. In 5 casus zou de werknemer zelf een rol gespeeld hebben, maar in geen enkele casus is er overeenstemming tussen het oordeel van de werknemer en dat van de bedrijfsartsen. Dit verschil in hoe men aankijkt naar de verzuimbegeleiding in het voorafgaande jaar blijkt ook uit de bevinding dat bij 8 casus alleen de

\begin{tabular}{|c|c|c|c|c|c|}
\hline \multirow[b]{2}{*}{ Domeinen } & \multicolumn{3}{|c|}{$\begin{array}{l}\text { Werknemer én bedrijfsarts zien } \\
\text { gemiste kans/verbeterpunten } \\
(n=11)\end{array}$} & \multirow[t]{2}{*}{$\begin{array}{l}\text { Werknemer } \\
\text { anders/beter } \\
(n=8)\end{array}$} & \multirow[t]{2}{*}{$\begin{array}{l}\text { Bedrijfsarts: } \\
\text { gemiste kans } \\
(n=17)\end{array}$} \\
\hline & beiden ja & $\begin{array}{l}\text { alleen } \\
\text { wn ja }\end{array}$ & $\begin{array}{l}\text { alleen } \\
\text { ba ja }\end{array}$ & & \\
\hline Curatieve zorg & 7 & 1 & 2 & 5 & 11 \\
\hline Arbozorg & 2 & 2 & 3 & 1 & 5 \\
\hline Werk(gever) & 2 & 1 & - & 6 & 5 \\
\hline Werknemer & - & 2 & 3 & 4 & 3 \\
\hline
\end{tabular}


werknemer verbeterpunten en/of gemiste kansen signaleert en in 17 andere casus alleen de bedrijfsarts. Van de 33 door de werknemers genoemde domeinen met gemiste kansen en de 43 door de bedrijfsartsen genoemde, beperkt de overeenstemming zich tot II.

Curatieve sector (dezelfde casus)

I Snellere diagnostiek (tweede aandoening) en snellere gerichte behandeling zou tot sneller herstel hebben geleid (bedrijfsarts).

I Te lange wachttijden bij de specialist. Wordt te lang aan het lijntje gehouden. Tweemaal MRI-scan. Totaal 5 maanden aangeknoeid (werknemer).

Aanwezigheid van een provider

of een re-integratiebedrijf

Arbodiensten en/of werkgevers kunnen afspraken maken met een provider of een re-integratiebedrijf voor interventies ter bevordering van de werkhervatting bij werknemers met (dreigend) langdurig verzuim vanwege psychische klachten en/of klachten van het bewegingsapparaat. Het is voorstelbaar dat het verzuim van werknemers die gebruik hebben kunnen maken van deze voorziening, minder vaak een verzuimduur hebben van één jaar of langer en/of dat er bij deze werknemers minder vaak gemiste kansen in het verzuimtraject optreden. Deze pilot laat het niet toe om iets te zeggen over de verzuimduur maar wel over de gemiste kansen. Het blijkt dat bij 36 werknemers die toegang hadden tot deze voorziening, de bedrijfsarts in $39 \%$ van de gevallen gemiste kansen signaleerde tegenover $64 \%$ van de 36 werknemers die geen toegang hadden tot deze voorziening (verschil significant; chikwadraattest $p=0,033)$. Bij de antwoorden van de werknemers ontbreekt dit verschil. Van de werk-

Domein arbozorg (bedrijfsarts):

I Te lang afwachtend beleid door begeleiding door niet-medicus die geen medische vragen mag stellen, waardoor te late signalering van medisch stagnatie.

I Werknemer is niet bij juiste re-integratiebureau spoor 2 terechtgekomen. Werkgever heeft bureau ingeschakeld en arbodienst onvoldoende geïnformeerd. $\mathrm{Nu}$ wordt in overleg met werkgever-werknemer voor een ander bureau gekozen. nemers die volgens de bedrijfsarts toegang hebben tot een provider, geeft $36 \%$ aan dat er gemiste kansen zijn tegen $37 \%$ van de werknemers die geen toegang tot een provider hebben.

Wat doet de bedrijfsarts bij gesignaleerde gemiste kansen?

De bedrijfsartsen vonden bij 37 casus dat er kansen waren gemist en bij 7 daarvan vonden ze nadere actie niet meer zinvol. Van de resterende 30 casus ondernamen de bedrijfsartsen actie in 26 casus (tabel 3). Gevraagd naar de beste acties bij de onderzochte casus noemden bedrijfsartsen vooral contact met de curatieve sector en de werkgever om te overleggen, informatie op te vragen of feedback te geven. In werkelijkheid namen ze vooral contact op met de werkgever.

De bedrijfsarts onderneemt ook acties op domeinen waar hij geen gemiste kans(en) heeft gesignaleerd. Zo zou de bedrijfsarts in I 8 casus willen overleggen met, of informatie aanvragen bij, de werkgever en ging hij in 24 van de 37 casus richting de werkgever echt iets doen.

Als er geen kansen waren gemist, zou volgens de bedrijfsartsen bij het merendeel van de 37 werknemers de gezondheid sneller zijn hersteld $(76 \%)$, het verzuim minder lang hebben geduurd (70\%) en minder arbeidsongeschiktheid zijn opgetreden (68\%).

\section{BESCHOUWING}

In dit onderzoek is getracht zicht te krijgen op het fenomeen van de gemiste kansen in de verzuimbegeleiding. De bedoeling was om I 5 bedrijfsartsen ieder (alle) I5 achtereenvolgende gevallen te laten selecteren zodat er van 225 gevallen informatie van bedrijfsarts én werknemer zou zijn. De bereidwilligheid van de bedrijfsartsen was er wel, maar de hectiek van alledag maakte dat niet alle verzuimgevallen werden ingesloten in het onderzoek en/of dat sommige bedrijfsartsen er niet aan toekwamen om casus aan te leveren. Het resultaat is een pilot geworden, en generalisatie van de resultaten is niet mogelijk. Toch is het relevant om de resultaten te publiceren. Werknemers en bedrijfsartsen signaleren in ongeveer de helft van de verzuimgevallen na een jaar gemiste kansen in het verzuimtraject. De bedrijfsartsen spreken overwegend over mogelijk gemiste kansen en in minder mate over evident gemiste kansen. De werknemers geven vooral aan dat het verzuim korter had kunnen duren en in enkele gevallen voorkomen 


\begin{tabular}{|c|c|c|c|c|c|c|}
\hline \multirow[b]{2}{*}{ Domein } & \multirow[b]{2}{*}{$\begin{array}{l}\text { Aantal } \\
\text { gemiste } \\
\text { kansen }\end{array}$} & \multicolumn{4}{|c|}{ Idealiter zou de ba doen ... } & \multirow[b]{2}{*}{$\begin{array}{l}\text { ba gaat } \\
\text { echt iets } \\
\text { doen }\end{array}$} \\
\hline & & $\begin{array}{l}\text { helemaal } \\
\text { niets }\end{array}$ & $\begin{array}{l}\text { in dit } \\
\text { domein } \\
\text { niets }\end{array}$ & $\begin{array}{l}\text { overleg/info } \\
\text { opvragen }\end{array}$ & $\begin{array}{l}\text { feedback } \\
\text { geven }\end{array}$ & \\
\hline Curatieve zorg & 23 & 7 & 7 & 12 & 7 & 7 \\
\hline Arbozorg & 14 & 7 & 6 & 5 & 3 & 3 \\
\hline Werk(gever) & 13 & 7 & 1 & 8 & 7 & 11 \\
\hline Werknemer & 10 & 7 & 2 & 4 & 4 & 5 \\
\hline Aantal casus & 37 & 7 & & 30 & & 26 \\
\hline
\end{tabular}

had kunnen worden. Werknemers schrijven dit vooral toe aan de curatieve zorg en de werkgever, de bedrijfsarts vooral aan de curatieve zorg. Op casusniveau zijn werknemer en bedrijfsarts het in $35 \%$ van de gevallen eens dat er geen gemiste kansen waren. In $7 \%$ van de gevallen zijn ze het beiden volledig eens over het domein van de gemiste kansen en in $9 \%$ gedeeltelijk. Dat betekent dat in $49 \%$ van de gevallen bedrijfsarts en/of werknemer gemiste kansen signaleren, maar er geen overeenstemming is over de aard van de gemiste kansen. De toegang tot een provider of een re-integratiebedrijf lijkt de verzuimbegeleiding ten goede te komen in die zin dat de bedrijfsarts minder vaak gemiste kansen signaleert. De toegang tot een provider is niet van invloed op de mening van de werknemer. Die ziet even vaak gemiste kansen als hij toegang tot een provider heeft als wanneer hij geen toegang heeft. Bij signalering van een gemiste kans onderneemt de bedrijfsarts actie, vooral richting de werkgever.

Dit onderzoek is bij ons weten het eerste dat ingaat op het opschudmoment en de terugkijkfunctie. Zoals gezegd zijn de resultaten te beperkt om te generaliseren. Het is mogelijk dat de resultaten bij andere bedrijfsartsen en andere groepen werknemers anders zouden hebben gelegen.

De resultaten steunen de gedachte dat opschudden en terugkijken zin heeft, zowel voor de werknemer als de bedrijfsarts. Voor de werknemer omdat de verzuimbegeleiding een extra impuls krijgt waardoor de effectiviteit van de begeleiding mogelijk verbetert. De bedrijfsarts kan leren van gemiste kansen en ontstane situaties en daarmee kan hij de kwaliteit van zijn eigen handelen verbeteren. Niet alle gemiste kansen zullen alsnog kunnen worden gegrepen, maar alle winst is welkom.

Een aandachtspunt dat nader onderzoek behoeft, is de geringe overeenstemming tussen de visie van de werknemer en de bedrijfsarts. Van de 55 casus waarvan informatie beschikbaar is van de bedrijfsarts en van de werknemer, worden bij $65 \%$ gemiste kansen gesignaleerd. Slechts bij $20 \%$ van de casus is volgens werknemer én bedrijfsarts sprake van een gemiste kans. Ook van de 33 door de werknemer genoemde domeinen met gemiste kansen en de 43 die de bedrijfsartsen noemen, overlappen er slechts I I. Dit lijkt illustratief voor de constatering in eerder onderzoek dat door uiteenlopende omstandigheden en belangen informatie niet altijd open wordt gedeeld tussen de centrale actoren en er soms sprake is van volkomen miscommunicatie tussen verschillende actoren. ${ }^{5}$ Een zo kleine overeenstemming in de visie tussen bedrijfsarts en werknemer roept de vraag op naar de validiteit van de constateringen van gemiste kansen door de bedrijfsartsen. Validering van de invulling van de terugkijkfunctie is wenselijk om tot de juiste leermomenten te komen voor de bedrijfs- en verzekeringsarts.

Al met al zijn wij van mening dat dit type onderzoek op grotere en meer representatieve schaal zou moeten worden herhaald, zodat in kaart gebracht kan worden hoe vaak gemiste kansen voorkomen en in welke domeinen ze voorkomen, opdat elk domein er zijn lering uit kan trekken. Voor de professie van de bedrijfsartsen, die in dit onderzoek de zelfkritiek niet uit de weg gingen, is het doen van opschudden en terugkijken een niet te missen kans! Een gezamenlijke invulling van het opschudmoment door bedrijfsartsen, werknemers en werkgevers waarbij kritisch teruggekeken wordt, biedt deze drie actoren de beste kansen op leermomenten. Idealiter wordt daar bij de gevallen die aan de poort van de WIA staan, de visie van de verzekeringsarts als invulling van de wettelijk voorgeschreven beoordeling bij betrokken. Een eerste stap op weg naar verbetering is overeenstemming tussen alle actoren over waar het aan schort.

LITERATUUR

I. Centraal Bureau voor de Statistiek, 2008. http://stat line.cbs.nl/statweb.

2. OECD. Sickness, disability and work. Breaking the bar- 
riers. Denmark, Finland, Ireland and the Netherlands. Volume 3. Parijs: OECD, 2008.

3. OECD. Sickness, disability and work. Keeping on track in the economic downturn. Parijs: OECD, 2009.

4. Gezondheidsraad. Beoordelen, behandelen en begeleiden. Den Haag: Gezondheidsraad, 2005.

5. Knegt R, Besseling JJM, Hoffius R, et al. Scènes uit een reïntegratieproces. Hoofddorp: TNO, 2004.
6. Kremer AM, Steenbeek R. Avoidable sickness absence in a Dutch working population. J Occup Rehabil 20I0; 20: 8I-89.

Het onderzoek is gefinancierd vanuit het TNO kennisontwikkelingsproject Werk en Arbeidsgeschiktheid.

De auteurs verklaren dat er geen sprake is van belangenconflicten.

\section{BOEKBESPREKING}

\section{Motiveren kun je leren, gidsen naar gezond gedrag}

Pauline Dekker en Wanda de Kanter. Thoeris, Amsterdam, 20Io. ISBN 97890722 I 9497, I76 pagina's, prijs I 9,95 euro.

Dokters verwaarlozen hun patiënten als zij hen niet aanspreken op ongezond gedrag. De ogen sluiten voor een zelfvernietigende leefstijl is dan ook geen optie. Deze visie motiveerde Dekker en De Kanter, beiden longarts, om het niet op te geven als patiënten zichzelf te gronde bleven richten. Steeds opnieuw spoorden zij hun patiënten aan om te stoppen met roken. Zij zagen echter ook dat hun inzet niet veel uithaalde. Tot zij in contact kwamen met motiverende gespreksvoering. De auteurs schreven eerder over deze methode in Nederland stopt! Met roken. Hun nieuwe boek noemen zij niet minder dan hét handboek voor hulpverleners.

In Motiveren kun je leren wordt de motiverende gespreksvoering van Miller en Rollnick stapsgewijs besproken. Deze methode begint ermee dat je de patiënt toestemming vraagt om advies te mogen geven. Daarna worden de redenen onderzocht die de patiënt heeft voor zijn ongezonde gedrag, en vervolgens de motivatie die hij heeft om toch te veranderen. Uitgangspunt is dat iemand altijd ambivalent staat in zijn ongezonde gedrag en dat je hem kunt helpen zich bewust te worden van die innerlijke twijfel. Daaronder ligt de visie dat gezond gedrag beter is dan ongezond gedrag en dat de hulpverlener dat standpunt niet moet loslaten.

Dekker en De Kanter illustreren hun verhaal met dialogen uit de praktijk en met spotprentjes en strips. Het taalgebruik lijkt vooral op niet-artsen gericht. Daarmee is het een laagdrempelig boek geworden. Inhoudelijk is het wat veel van alles wat, waarbij na het deel over motiveren allerlei onderwerpen in een rommelige structuur bij elkaar staan. Literatuurverwijzingen ontbreken. Het boek bevat veel herhalingen. Geen handboek voor artsen dus. Door de herhaling wordt de boodschap echter wel duidelijk. Dat komt goed uit, want hulpverleners kunnen er niet omheen om met patiënten over roken te spreken. ${ }^{\mathrm{r}}$

Voor bedrijfsartsen zijn interventies tegen tabaksverslaving niet nieuw meer en verzekeringsartsen hebben eerder kennis gemaakt met motiverende gespreksvoering. ${ }^{2,3}$ Motiveren kun je leren vormt een makkelijke ingang om kennis hierover op te frissen. Het enthousiasme van de auteurs en hun gedrevenheid om niet op te geven patiënten het goede pad op te gidsen, werken hierbij aanstekelijk en motiverend.

Ingeborg van den Bold

\section{LITERATUUR}

I. Everaert C. De CBO-richtlijn Behandeling van tabaksverslaving: commentaar vanuit de bedrijfsgezondheidszorg. Tijdschr Bedrijfs Verzekeringsgeneeskd 20IO; I8: 222-224.

2. Everaert C, Elvers H. Telefonische coaching bij stoppen met roken is effectief en doelmatig na een PMO. Tijdschr Bedrijfs Verzekeringsgeneeskd 20I0; I8: 255259.

3. Verzekeringsgeneeskundig protocol Participatiegedrag. Verzekeringsgeneeskundig Instituut, 2010, pp. $75-78$ 